\title{
Quench Sensitivity and Phase Transformation Kinetics of AlSi7MnMg High Pressure Vacuum Die Casting
}

\author{
Mengyun Liu', Zhan Zhang ${ }^{1, *}$, Francis Breton ${ }^{2}$ and X.-Grant Chen ${ }^{1}$ \\ ${ }^{1}$ Department of applied science, University of Quebec at Chicoutimi, Saguenay, QC, Canada, G7H 2B1 \\ ${ }^{2}$ Arvida Research and Development Centre, Rio Tinto, Saguenay, QC, Canada, G7S 4K8
}

\begin{abstract}
The quench sensitivity of an AlSi7MnMg alloy in high-pressure vacuum die (HPVD) casting was investigated by time-temperature-transformation and time-temperature-property diagrams with an interrupted quench technique. The quench sensitive temperature range of the alloy is from 260 to $430{ }^{\circ} \mathrm{C}$ and its nose temperature is $350{ }^{\circ} \mathrm{C}$. The mechanical strength versus cooling rates of the HPVD casting was predicted using quench factor analysis method and verified by experimental results. The critical cooling rate is $6{ }^{\circ} \mathrm{C} / \mathrm{s}$ to remain $95 \%$ of the maximal mechanical strength. The coefficients $k_{2}-k_{5}$, related to the nucleation and precipitation kinetics of TTP curves, and phase transformation diagrams were determined. The precipitation of $\mathrm{Mg}_{2} \mathrm{Si}$ phase in the castings was observed during isothermal treatment using transmission electron microscope. Moreover, the quench sensitivity and kinetics of the phase transformation of A1Si7MnMg alloy and AlSi10MnMg alloys were compared. It reveals that the quench sensitivity and phase transformation rate of the former are lower than that of the latter.
\end{abstract}

\section{Introduction}

AlSi7MnMg (Aural'TM-5) alloy has been widely applied in high pressure vacuum die (HPVD) castings due to its very good fluidity and castability, particularly suitable for thin-wall and large complex cast structural components [1]. The AlSi7MnMg die casting alloy is heat-treatable and weldable, and thus its mechanical properties can be greatly enhanced through heat treatment, because the vacuum system used during the die casting process removes the entrapped air in die cavity during filling and consequently limits the formation of blisters during solution heat treatment $[2$, 3].

Quenching is one of important steps in precipitationhardening heat treatment processes. Excessive rapid quenching can introduce severe residual stress and may lead to distortion at thin sections. Insufficient quenching can result in a low level of supersaturated solutes in the matrix, and eventually reduce the strengthening effect during artificial aging. Therefore, it is important to select an optimal quenching rate in the heat treatment. Quench sensitivity is related to the formation of a non-hardening phase during quenching. Time-temperaturetransformation (TTT) and time-temperature-precipitate (TTP) diagrams are broadly used to study the quench sensitivity because these diagrams deliver important information, such as the critical time and nose temperature for precipitation during quenching [4]. An interrupted quenching technique with series of isothermal heating tests has been applied to construct these diagrams [4]. Quench factor is defined as the severity of a quench and can be quantified to a single number using integrated cooling rate and TTP curves, and it has been used to predict properties under certain cooling rates [5]. By quenching samples in water at various temperatures, Zhang et al. [6] studied the quench sensitivity of $\mathrm{A} 1-7 \% \mathrm{Si}-0.4 \% \mathrm{Mg}$ (A356) permanent mold (PM) castings. As the quench rate decreases from 250 ${ }^{\circ} \mathrm{C} / \mathrm{s}$ to $0.5^{\circ} \mathrm{C} / \mathrm{s}$, the ultimate tensile strength and yield strength of peak-aged A356 castings decreased by approximately 27 and $33 \%$, respectively. Ma et al. [7] used the quench factor analysis method to predict the effect of quench rates on mechanical properties of A356 PM castings, and the predicted results were in good agreement with the experimental data. Recently, Liu et al. [8] investigated quench sensitivity of AlSi10MnMg PM and HPVD castings. They demonstrated that the casting process had an impact on quench sensitivity of castings. HPVD castings were more quench sensitive than PM castings mainly due to the fine grain size and large amount of grain boundaries in HPVD castings.

The aim of the study is to investigate the quench sensitivity, phase transformation kinetics, and the effect of the quench rate on mechanical properties of the AlSi7MnMg HPVD castings. Moreover, the characteristics of TTP diagrams of both AlSi7MnMg and $\mathrm{AlSi} 10 \mathrm{MnMg}$ alloys are analyzed to understand the influence of alloy chemical compositions on the quench sensitivity.

\footnotetext{
* Corresponding author: zhan zhang@uqac.ca
} 


\section{Experimental}

Both AlSi7MnMg (Aural $\left.{ }^{\text {TM}}-5\right)$ and AlSi10MnMg (Aural ${ }^{\mathrm{TM}}-3$ ) HPVD casting samples were produced by a cold chamber vacuum die casting machine (Buhler 26D, Markham, ON, Canada) equipped with a Castool vacuum system (Uxbridge, ON, Canada). The dimension of the cast plates is $220 \mathrm{~mm} \times 65 \mathrm{~mm}$ with a thickness of $2.5 \mathrm{~mm}$. Table 1 lists the chemical compositions of the two alloy samples analyzed with an optical emission spectrometer.

Table 1. Chemical composition (wt.\%) of experimental alloys

\begin{tabular}{|l|l|l|l|l|l|l|l|}
\hline Alloys & $\mathrm{Si}$ & $\mathrm{Fe}$ & $\mathrm{Mn}$ & $\mathrm{Mg}$ & $\mathrm{Ti}$ & $\mathrm{Sr}$ & $\mathrm{Al}$ \\
\hline AlSi7MnMg & 7.40 & 0.17 & 0.49 & 0.20 & 0.08 & 0.018 & bal. \\
\hline AlSi10MnMg & 10.10 & 0.18 & 0.50 & 0.55 & 0.06 & 0.012 & bal. \\
\hline
\end{tabular}

The size of the samples used in isothermal holding tests is $20 \mathrm{~mm} \times 20 \mathrm{~mm}$ cut from HPVD cast plates. The samples were solution-heat-treated at $500{ }^{\circ} \mathrm{C}$ for $3 \mathrm{~h}$, and then immediately transferred into a salt bath at 250-450 ${ }^{\circ} \mathrm{C}$ for different holding times. The salt bath temperature was continuously monitored and maintained at $\pm 1{ }^{\circ} \mathrm{C}$ of the targeted temperature. After isothermal holding, the samples were quenched in water at room temperature, and then artificially aged at $170{ }^{\circ} \mathrm{C}$ for $2.5 \mathrm{~h}$. An electrical conductivity tester (Sigmascope SMP10) was used to evaluate the electrical conductivity of asquenched samples. Four measurements were conducted for each sample. Conventional metallographic polishing process was applied for the microstructure observation. Vickers hardness were measured using a Vickers hardness tester (Nextgen NG-1000CCD) with a load of $100 \mathrm{~g}$ and a dwell time of $15 \mathrm{~s}$, according to the ASTM E92. The average values were reported from 10 measurements.

The microstructures of the samples were examined by an optical microscope coupled with an image analyzer (CLEMEX), and a scanning electron microscope (JSM-6480LV). The phase precipitation was observed using a transmission electron microscope (JEM-2100). TEM samples were prepared by a twin-jet electro-chemical polisher in a solution of $25 \%$ nitric acid in methanol at $-25{ }^{\circ} \mathrm{C}$. To verify predicted mechanical properties at various quench rates, the solution-treated samples were quenched in different media (still or forced air, fiberglass insulator, oil at different temperatures), followed by an aging treatment at $170{ }^{\circ} \mathrm{C}$ for $2.5 \mathrm{~h}$. Then, the microhardness of the samples was measured to determine the mechanical properties at different quench rates.

\section{Results and discussion}

\subsection{Time-temperature-transformation diagram}

During isothermal treatment, supersaturated aluminum matrix would decompose to form precipitates, which is corresponding to the changes in electrical conductivity (EC) of samples. The EC evolution of the quenched $\mathrm{AlSi} 7 \mathrm{MnMg}$ samples at different isothermal temperatures are shown in Fig. 1a. At the first stage, the EC increases rapidly then more slowly to finally reach a stable value during isothermal holding. At $350{ }^{\circ} \mathrm{C}$, the EC increasing rate is faster than that at lower or higher temperatures. The EC of the quenched samples after solution treatment is $38.5 \%$ IACS, which represents a supersaturated solid solution state, whereas the EC of isothermal holding at $350{ }^{\circ} \mathrm{C}$ for $27 \mathrm{~h}$ increases to $43.5 \%$ IACS, which represents a complete decomposition of supersaturated solid solution. The time-temperature transformation (TTT) diagram was constructed using the values of $10 \%, 20 \%, 30 \%$ and $40 \%$ of the EC difference between the supersaturated and the complete decomposition samples. The measured data based on Fig. 1a and the mathematical fitted curves are shown in Fig. 1b. The TTT contours show a "C" shape. The nose temperature of the curves is $350{ }^{\circ} \mathrm{C}$, and the critical time, corresponding to the minimum time required for $10 \%$ precipitate transformation, is 16 seconds (Fig. 1b). Moreover, the quench sensitive temperature range is $260-430{ }^{\circ} \mathrm{C}$. In this temperature range, the $\mathrm{EC}$ varies rapidly.
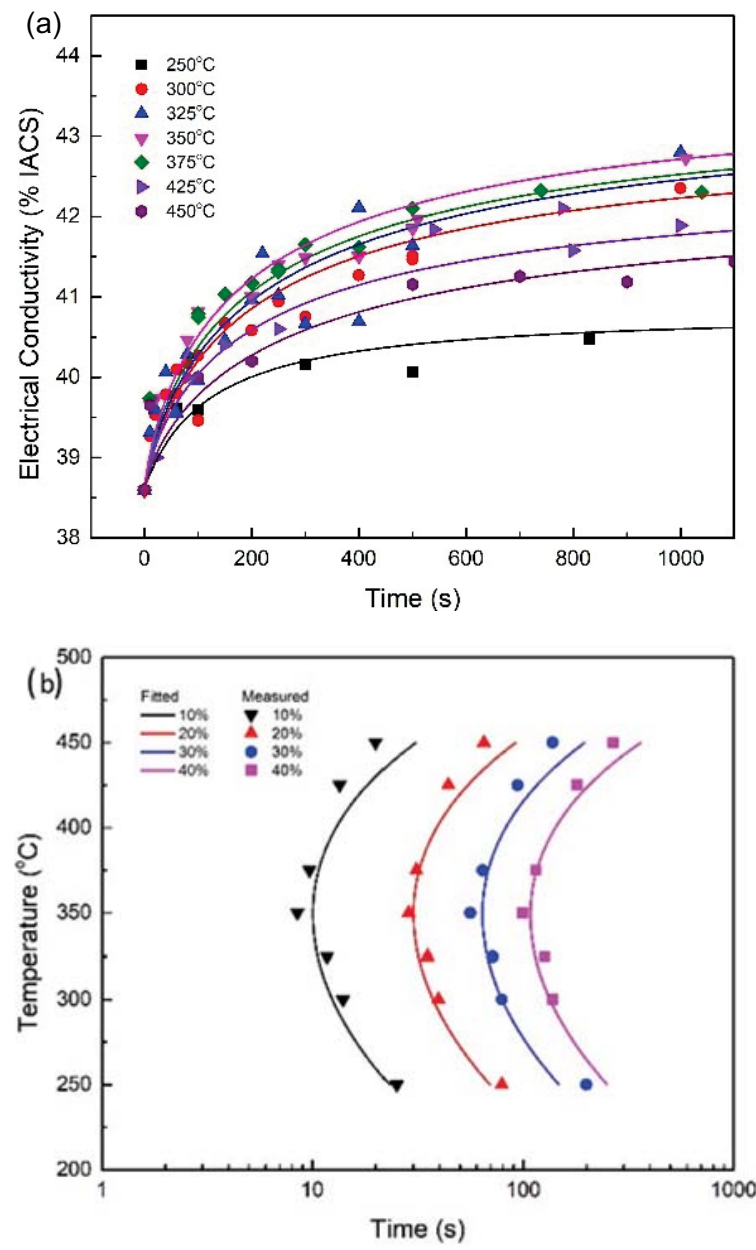

Fig.1. Electrical conductivity evolution at different isothermal temperatures as a function of holding time (a); TTT diagram of AlSi7MnMg HPVD castings (b). The lines in (b) are the fits to the experimental data by using Equation (1). 


\subsection{Time-temperature-property diagram and mechanical property prediction}

The hardness varies with the evolution of precipitation in aluminum alloys during heat treatments. The hardness of the AlSi7MnMg HPVD castings under T6 condition $\left(500{ }^{\circ} \mathrm{C}\right.$ for $3 \mathrm{~h}$ followed by $170{ }^{\circ} \mathrm{C}$ for $2.5 \mathrm{~h}$ ) is 73.3 $\mathrm{HV}$, which is considered to be the highest hardness of cast samples, but it decreases with an increase of the holding time at isothermal temperatures. Fig. 2a illustrates the hardness evolution of cast samples during isothermal holding. Generally, the hardness decreases rapidly at the first stage, then the decrease rate is significantly slowdown. At $350{ }^{\circ} \mathrm{C}$, the hardness decrease rate is faster than that at lower or higher temperatures. TTP curves can be mathematically described in Equation 1 [9]:

$$
C_{t}(T)=-k_{1} k_{2} \exp \left[\frac{k_{3} k_{4}^{2}}{R T\left(k_{4}-T\right)^{2}}\right] \exp \left(\frac{k_{5}}{R T}\right)
$$

Where $C_{t}(T)$ is the critical time for a certain fraction of solutes to precipitate; note that the fraction of solutes precipitated corresponds to the fraction of hardness loss in TTP diagram; $k_{1}$ is the natural logarithm of the unprecipitated fraction during isothermal holding; $k_{2}$ is the constant associated with the reciprocal of the number of nucleation sites; $k_{3}$ is the constant corresponding to the nucleus energy; $k_{4}$ is the constant related to the solvus temperature; $k_{5}$ is the constant related to the activation energy for diffusion; $R$ is the mole gas constant; $T$ is the temperature $(K)$. The coefficients in Equation 1 were determined by non-linear least squares regression based on the data in Fig. $2 \mathrm{a}$ and are listed in Table 2.

Table 2. Coefficients of TTP curves of experimental alloys.

\begin{tabular}{|c|c|c|c|c|}
\hline Castings & $k_{2}(\mathrm{~s})$ & $k_{3}(\mathrm{~J} / \mathrm{mol})$ & $k_{4}(\mathrm{~K})$ & $k_{5}(\mathrm{~J} / \mathrm{mol})$ \\
\hline Aural-5 & $2.38 \times 10^{-6}$ & $2.87 \times 10^{3}$ & $9.45 \times 10^{2}$ & $7.42 \times 10^{3}$ \\
\hline Aural-3 $[8]$ & $1.92 \times 10^{-6}$ & $2.48 \times 10^{3}$ & $9.55 \times 10^{2}$ & $7.30 \times 10^{3}$ \\
\hline
\end{tabular}

The TTP diagram with the contours of $99.5 \%$, $95 \%$, and $90 \%$ of the maximal hardness of the samples, is shown in Fig. 2b. The measured data in Fig. $2 b$ are from the curves in Fig. 2a, and the mathematically fitted curves are based on the calculation with Equation 1. The contours in TTP diagram also show "C" shape. The nose temperature and quench sensitive temperature range in the TTP diagram are similar to those in TTT diagram. The critical time at the nose temperature is $2.4 \mathrm{~s}$ to obtain $99.5 \%$ maximum hardness.

The quench factor analysis is widely applied to predict the effect of cooling rate (quench rate) on mechanical property, and the quench factor $\tau$, can be calculated using Equation 2 [9]:

$$
\tau=\sum_{t_{o}}^{t_{f}} \frac{\Delta t}{C_{t}(T)}
$$

Where $C_{t}(T)$ is the critical time for a specific amount of solutes to precipitate; $t_{0}$ is the time at the start of the quench; $t_{f}$ is the time at the end of the quench; and $\Delta t$ is time step. Then, the predicted properties at various cooling rates can be expressed as Equation 3 [9]:

$$
\sigma=\sigma_{\text {mux }} \exp \left(k_{1} \tau\right)
$$

Where $\sigma$ is the predicted property; $\sigma_{\max }$ is the property attainable with an infinite quench rate; $k_{l}$ is $\ln (0.995)$. Equation 4 describes the property drop $\Delta \%$, as a function of the quench factor [10]:

$$
\Delta \%=1-\exp \left(k_{1} \mathrm{\tau}\right)
$$
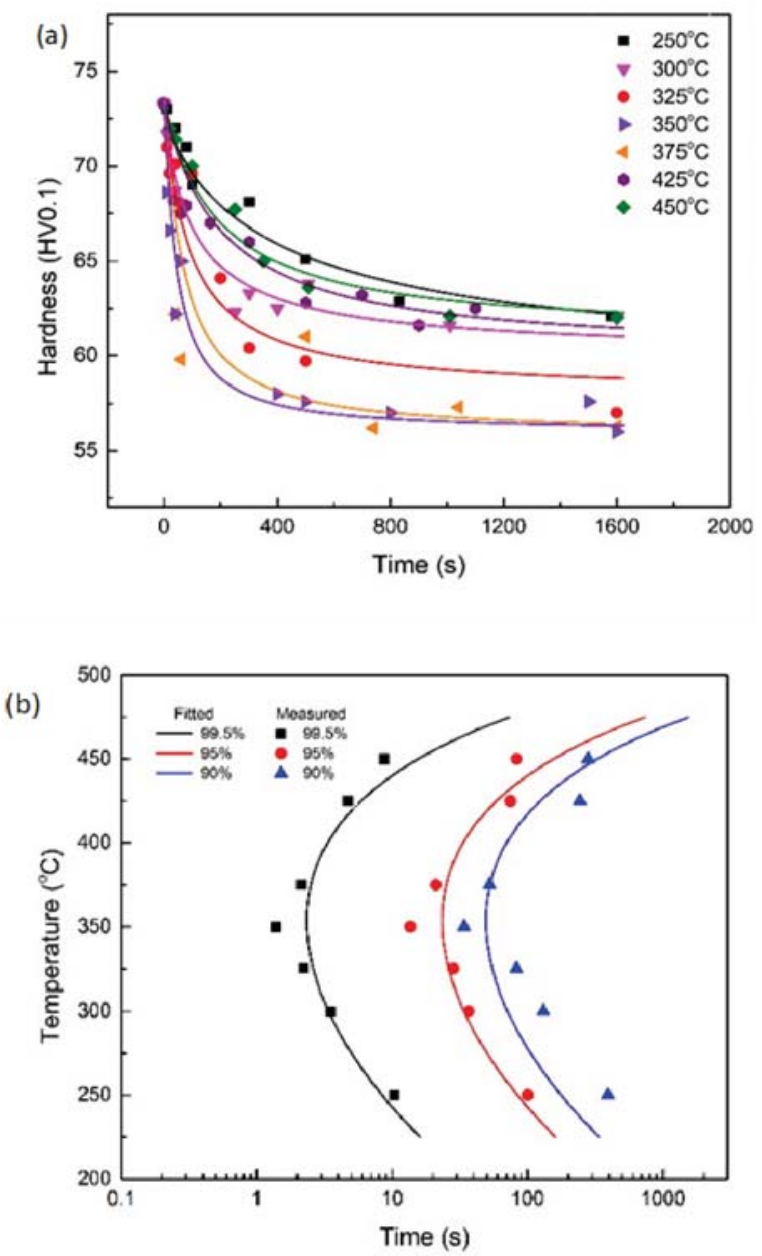

Fig. 2. Hardness evolution at different isothermal temperatures as function of holding time (a); TTP diagram of AlSi7MnMg HPVD samples (b).

$\Delta \mathrm{t}=0.01 \mathrm{~s}$ has been selected in Equation 2 because the temperature decrease should be less $25{ }^{\circ} \mathrm{C}$ during each time step to ensure the accuracy of the quench factor calculation $[8,11]$. When the quench sensitive temperature range is considered in quench factor calculation, the effect of the temperature range on quench factor calculation is ignored [12]. In this study, the range of $260-430{ }^{\circ} \mathrm{C}$ is applied to the quench factor calculation. The effect of cooling rate (quench rate) on the quench factor and predicted hardness is illustrated in Fig. 3a. As the cooling rate increases, at the beginning, the quench factor decreases rapidly, but the decrease of 
the quench factor becomes slow when the cooling rate reaches a certain value. Conversely, the predicted hardness initially increases rapidly, then the increase becomes slow. Fig. $3 \mathrm{~b}$ demonstrates the effect of the cooling rate on hardness drop. When the cooling rate increases, the hardness drop decreases. It can be seen that the hardness drop is less than $5 \%$ when the cooling rate is over $6{ }^{\circ} \mathrm{C} / \mathrm{s}$. This cooling rate is referred as the critical cooling rate, $\mathrm{Cr}$. In the other words, when the cooling rate is higher than $6{ }^{\circ} \mathrm{C} / \mathrm{s}$, higher than $95 \%$ of maximal mechanical strength of the samples can be obtained. In Fig. 3b, the dark line represents the predicted data based on Equation 4, and the red dots are the measured hardness of the samples subjected to quench experiments at various cooling rates. The predicted results are basically consistent with experimental data.
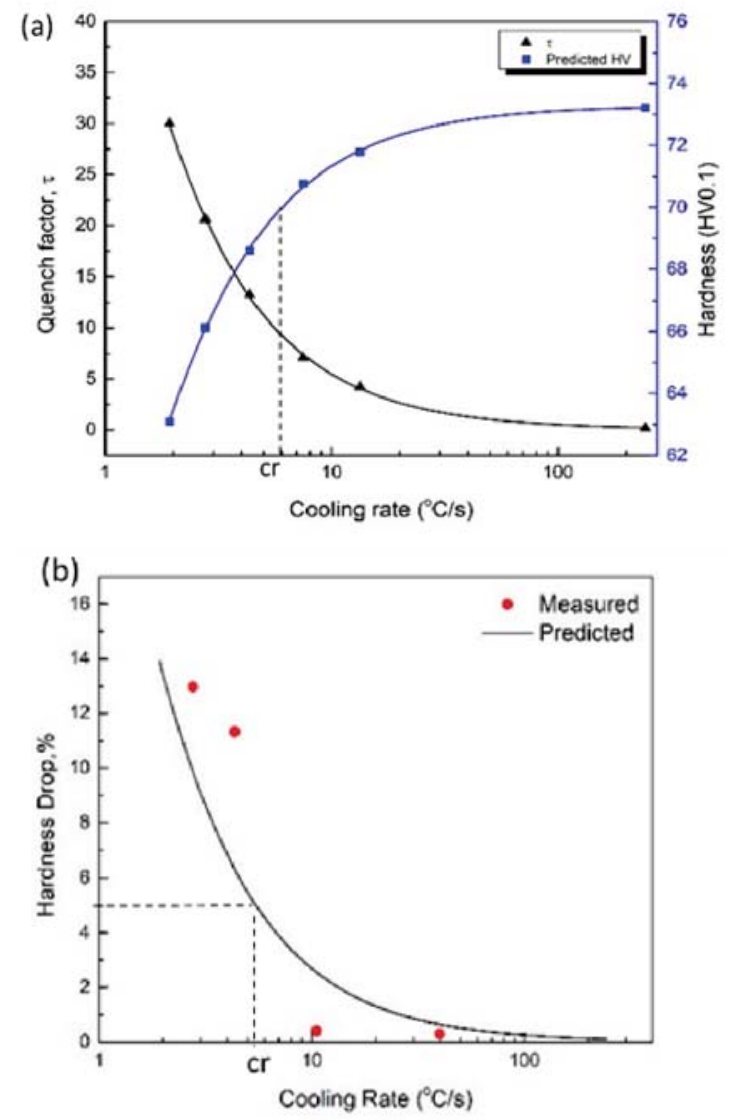

Fig. 3. Effect of cooling rate on quench factor and predicted hardness (a); Drop in the hardness vs. cooling rate of AlSi7MnMg samples (b).

\subsection{Precipitation during isothermal treatment}

Quench sensitivity of $\mathrm{Al}-\mathrm{Si}-\mathrm{Mg}$ die casting alloys is mainly determined by the precipitation of a nonhardening phase during quenching, which would negligibly affect the alloy strengthening during the subsequent aging treatment. The precipitates at the nose temperature $\left(350{ }^{\circ} \mathrm{C}\right)$ for $300 \mathrm{~s}$ in the isothermal holding were examined, as shown in Fig. 4. Few of needle-like precipitates with length of $0.5-1 \mu \mathrm{m}$ and a thickness of 20-50 nm were observed in the aluminum matrix (Fig. 4a), while a large number of particles with an equivalent diameter of $0.2-0.5 \mu \mathrm{m}$ appears along the grain boundaries (Fig. 4b). These needle-like precipitates in the aluminum matrix and particles in the grain boundaries are identified as equilibrium $\beta-\mathrm{Mg}_{2} \mathrm{Si}$ phase. It is evident that such large and coarse precipitates have only negligible effect on the alloy strength, and it causes a low level of solute concentrations $(\mathrm{Mg}$ and $\mathrm{Si})$ in the matrix, resulting in a reduced hardening effect during subsequent aging.
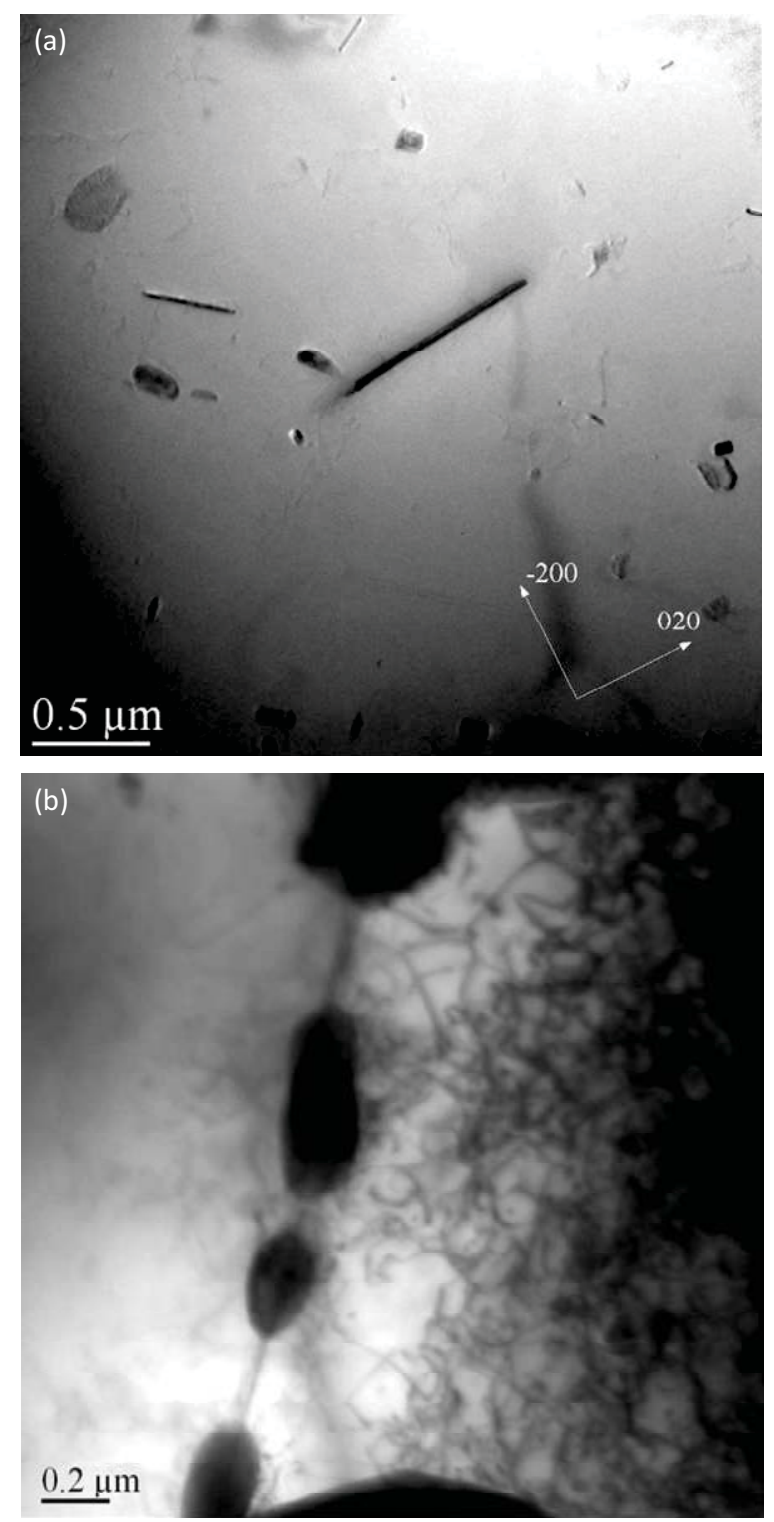

Fig. 4. TEM bright field images of the AlSi7MnMg HPVD sample isothermally treated at $350{ }^{\circ} \mathrm{C}$ for $300 \mathrm{~s}$. Equilibrium $\beta$ $\mathrm{Mg}_{2} \mathrm{Si}$ precipitated in the aluminum matrix (a) and along the grain boundary (b). 


\subsection{Phase transformation kinetics}

Avrami kinetics equation, $\psi=1-\exp \left(-k t^{n}\right)$, is generally applied to describe the kinetics of a phase transformation [13, 14], and here, the phase transformation refers to large $\mathrm{Mg}_{2} \mathrm{Si}$ particles precipitated from the supersaturated aluminum matrix, which would not contribute the alloy strengthening during aging treatment. Where $\psi$ is the volume fraction of the precipitation at the time $t, k$ is the Avrami constant depending on the nucleation rate and the growth rate, and $n$ is the Avrami exponent which is depending on the nucleation mechanism.
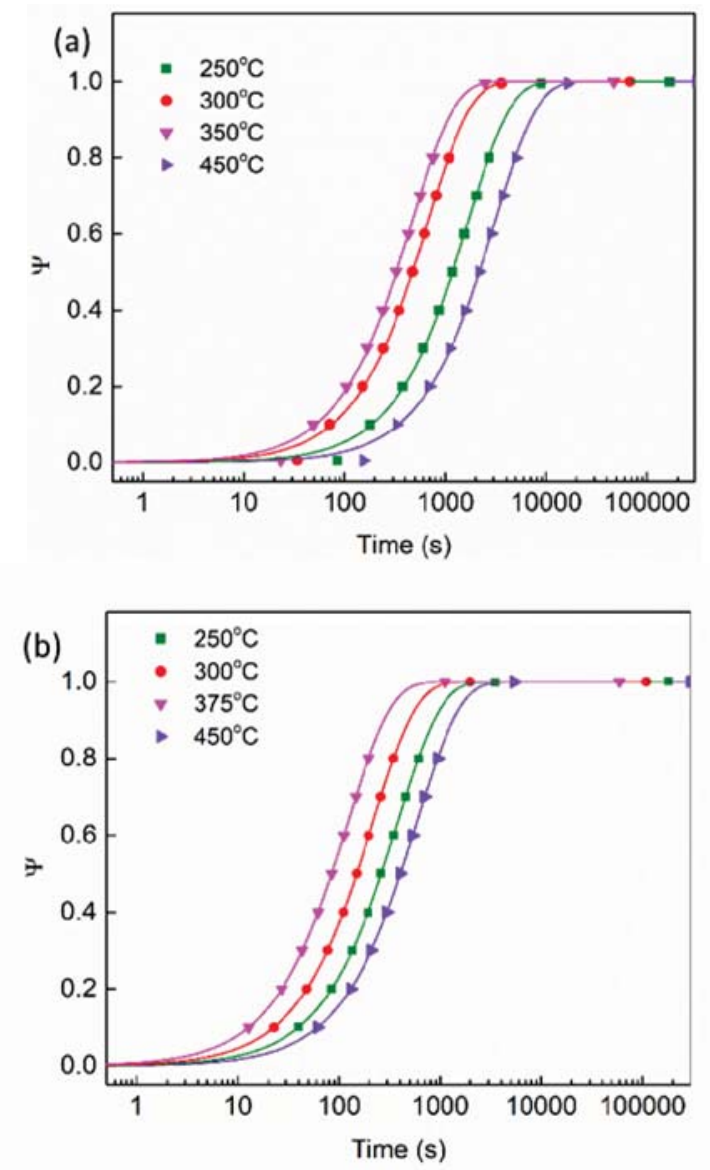

Fig. 5. Precipitate transformation as function of holding time during isothermal treatment for AlSi7MnMg (Aural-5) HPVD castings (a), and AlSi10MnMg (Aural-3) HPVD castings (b).

Table 3. Avrami kinetics equation parameters, $k$ and $n$, of Aural-5/3 HPVD castings.

\begin{tabular}{|c|c|c|c|c|c|}
\hline & Castings & $250{ }^{\circ} \mathrm{C}$ & $300^{\circ} \mathrm{C}$ & N.T. $^{*}$ & $450^{\circ} \mathrm{C}$ \\
\hline \multirow{2}{*}{$k$} & Aural-5 & 0.00050 & 0.00128 & 0.00186 & 0.00027 \\
\cline { 2 - 6 } & Aural-3 & 0.00286 & 0.00482 & 0.00731 & 0.00176 \\
\hline \multirow{2}{*}{$n$} & Aural-5 & 1.02335 & 1.02299 & 1.02284 & 1.02362 \\
\cline { 2 - 6 } & Aural-3 & 1.00201 & 1.00202 & 1.00331 & 1.00365 \\
\hline
\end{tabular}

*N.T. - the nose temperature: $350{ }^{\circ} \mathrm{C}$ for Aural-5; $375{ }^{\circ} \mathrm{C}$ for Aural-3.
The precipitated volume fraction $\psi$ at the time $t$ can be obtained from the TTP curves in Fig. 2, which (the marks) are shown in Fig. 5a, and the relative experimental points can be also found in Fig. 2. These marks would be fitted by an iterative non-linear fitting procedure with Avrami kinetics equation. The phase transformation diagram, fitted time-dependent volume fraction of the precipitates, of AlSi7MnMg HPVD castings at $250{ }^{\circ} \mathrm{C}, 300{ }^{\circ} \mathrm{C}, 350{ }^{\circ} \mathrm{C}$ and $450{ }^{\circ} \mathrm{C}$ is illustrated in Fig. 5a, and Avrami constant and exponent, $k$ and $n$, are listed in Table 3. As shown in Fig. 5a, the phase transformation rate $(d \psi / d t)$ is low at the beginning of isothermal treatment, but the rate then increases greatly and reaches a high value after an approximately 0.2 volume fraction of precipitates. However, the phase transformation rate decreases gradually when the volume fraction of the transformed phases is more than 0.8. The values of $k$ of AlSi7MnMg, listed in Table 3, vary with the isothermal temperatures. The sequence of the $k$ value is that $k$ at $350{ }^{\circ} \mathrm{C}$ (N.T.) $>$ at $300{ }^{\circ} \mathrm{C}>$ at $250{ }^{\circ} \mathrm{C}>$ at $450{ }^{\circ} \mathrm{C}$. Thus, the phase transformation rate at the nose temperature is larger than that at lower or higher temperatures because a large value of $k$ is relative to a rapid phase transformation rate [14]. Moreover, the shortest time to perform a certain phase transformation in the castings is at $350{ }^{\circ} \mathrm{C}$. For example, the time to perform $60 \%$ precipitate transformation is approximately $350 \mathrm{~s}$ at $350{ }^{\circ} \mathrm{C}$ (nose temperature), $500 \mathrm{~s}$ at $300{ }^{\circ} \mathrm{C}$, $1500 \mathrm{~s}$ at $250^{\circ} \mathrm{C}$, and $2000 \mathrm{~s}$ at $450{ }^{\circ} \mathrm{C}$, respectively. It further demonstrates that the maximum phase transformation rate in the isothermal treatment is at the nose temperature. The average phase transformation rate from 0.2 and 0.8 volume fraction is around $1 \times 10^{-3} \mathrm{~s}^{-1}$ (volume fraction per second) at the nose temperature, $350{ }^{\circ} \mathrm{C}$, for AlSi7MnMg.

The phase transformation diagram of AlSi10MnMg HPVD castings is determined based on the TTP diagram in the reference [8], as shown in Fig. $5 \mathrm{~b}$. And the values of $k$ and $n$ are listed in Table 3, respectively. The phase transformation tendency in AlSi10MnMg is similar to that in AlSi7MnMg. The $k$ value at $375^{\circ} \mathrm{C}$ is larger than that at $300{ }^{\circ} \mathrm{C}, 250{ }^{\circ} \mathrm{C}$ and $450{ }^{\circ} \mathrm{C}$, respectively. Compared with $\mathrm{AlSi} 7 \mathrm{MnMg}$, $\mathrm{AlSi10MnMg}$ has much larger $k$ values, and at their nose temperatures the $\mathrm{k}$ value of $\mathrm{AlSi} 10 \mathrm{MnMg}$ is about 4 times that of AlSi7MnMg. Moreover, the time to perform a certain amount of precipitate transformation for AlSi10MnMg is much shorter than that for AlSi7MnMg. For example, to perform the transformation of $60 \%$ precipitates, AlSi $10 \mathrm{MnMg}$ spends approximately $100 \mathrm{~s}$ at $375^{\circ} \mathrm{C}, 180 \mathrm{~s}$ at $300{ }^{\circ} \mathrm{C}$, $250 \mathrm{~s}$ at $250{ }^{\circ} \mathrm{C}$, and $500 \mathrm{~s}$ at $450{ }^{\circ} \mathrm{C}$, respectively. The average phase transformation rate in the range from 0.2 to 0.8 volume fraction is $3.8 \times 10^{-3} \mathrm{~s}^{-1}$, at the nose temperature, $375^{\circ} \mathrm{C}$. The average phase transformation rate of AlSi10MnMg is much higher than that of AlSi7MnMg.

There are two kinds of precipitation mechanisms in phase transformation, one is diffusion-controlled process, and the other is nucleation-controlled process [14]. The former occurs at the temperature lower than the nose temperature, while the latter conducts at the 
temperature higher than the nose temperature. In diffusion-controlled precipitation, when the value of Avrami exponent $n$ is approximately 1, precipitates have the morphologies of thickening of long cylinder or needle-like shapes whereas in nucleation-controlled precipitation, the precipitates are mainly formed at grain boundaries [14]. Therefore, according to the values of $n$ in Tables 3 and 4, the needle-like precipitates would be present in AlSiMnMg alloys when the phase transformation at a temperature lower than the nose temperature, but if the phase transformation occurs at a temperature higher than the nose temperature, the precipitates would be formed along grain boundaries. Actually, Fig. 4 and the reference [8] show the precipitate morphology and distribution as described above.

\subsection{Comparison of quench sensitivity and phase transformation kinetics between two alloys}

AlSi7MnMg and AlSi10MnMg are two most widely used Al-Si-Mg alloys for high pressure die castings. Fig. 6 illustrates TTP contours of $99.5 \%$ and $90 \%$ of maximal hardness for two alloys. And the characteristics of the TTP contours are listed in Table 4 . The critical time at the nose temperature in $99.5 \%$ of maximal hardness for AlSi7MnMg is longer than that for AlSi10MnMg. And the nose temperature of the former is lower than that of the latter. Moreover, the quench sensitive temperature range of the former is $10{ }^{\circ} \mathrm{C}$ narrower than that of the later. Similar phenomena were observed in the contours of $90 \%$ maximal hardness. In addition, the critical cooling rate of $\mathrm{AlSi} 7 \mathrm{MnMg}$ is $6{ }^{\circ} \mathrm{C} / \mathrm{s}$, but the rate of $\mathrm{AlSi} 10 \mathrm{MnMg}$ is $20^{\circ} \mathrm{C} / \mathrm{s}$. Hence, the quench sensitivity of AlSi7MnMg is lower than that of AlSi10MnMg.

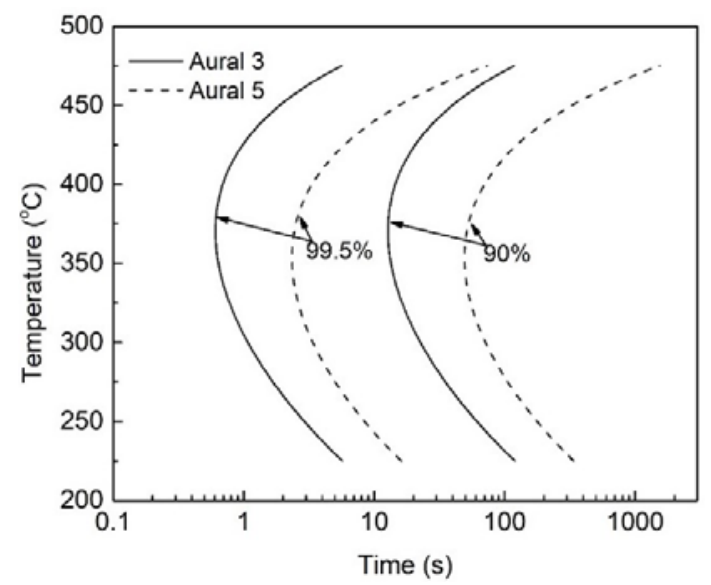

Fig. 6. TTP contours of $99.5 \%$ and $90 \%$ of maximum hardness of AlSi7MnMg (Aural ${ }^{\mathrm{TM}}-5$, dash line) and AlSi10MnMg (Aural ${ }^{\mathrm{TM}}-3$, solid line [8]).
Table 4. Parameters of $99.5 \%$ maximal hardness contours of Aural-3/5 HPVD castings.

\begin{tabular}{|c|c|c|c|}
\hline Castings & C.T. $^{*}$ & N.T. $^{* *}$ & T.R $^{* * *}$ \\
\hline Aural-5 & $2.4 \mathrm{~s}$ & $350^{\circ} \mathrm{C}$ & $260-430^{\circ} \mathrm{C}$ \\
\hline Aural-3 [8] & $0.6 \mathrm{~s}$ & $375^{\circ} \mathrm{C}$ & $270-450^{\circ} \mathrm{C}$ \\
\hline
\end{tabular}

${ }^{*}$ C.T.: the critical time at the nose temperature; ${ }^{* *}$ N.T.: the nose temperature; ${ }^{* *}$ T.R.: the quench sensitive temperature range.

According to the precipitate transformation kinetics of the two castings (Fig. 5), the average phase transformation rate of AlSi7MnMg is much slower than that of AlSi10MnMg. Moreover, the values of Avrami constant, $k$, corresponding to the nucleation rate and the growth rate, of AlSi7MnMg are much less than that of $\mathrm{AlSi} 10 \mathrm{MnMg}$ at different isothermal temperatures.

Generally, the phase transformation and quench sensitivity are mainly determined by nucleation and growth of precipitates during heat treatment [14]. The concentration of magnesium ( $0.20 \mathrm{wt} . \%)$ and silicon (7.4 wt.\%) in AlSi7MnMg is lower than that $(0.55$ wt.\% $\mathrm{Mg}$, 10.1 wt.\% Si) in AlSi10MnMg, respectively (see Table 1). The silicon maximal solubility in aluminum at $500{ }^{\circ} \mathrm{C}$ is $0.8 \mathrm{wt} . \%$. It is evident that magnesium solute atoms in $\mathrm{AlSi} 7 \mathrm{MnMg}$ matrix is lower than that in AlSi10MnMg matrix due to the difference in magnesium concentration between the two alloys. Consequently, the driving force for precipitate nucleation in AlSi7MnMg is lower than that in AlSi10MnMg because the driving force for precipitate nucleation is proportional to the concentration of the solutes supersaturated in the matrix [14]. Moreover, based on results of EBSD grain orientation maps listed in Table 5, the grain size of AlSi7MnMg is larger than that of AlSi10MnMg, whereas the length of grain boundaries in the former is much shorter than that in the latter. Therefore, nucleation sites for precipitates in AlSi7MnMg would be less than that in AlSi10MnMg because the grain boundaries provided potential sites for the precipitate nucleation (see Fig. 4b). In addition, grain boundaries supply fast solute diffusion channels, hence, they facilitate the growth of phases during heat treatment.

Table 5. Grain size and grain boundary length of HPVD castings.

\begin{tabular}{|c|c|c|}
\hline Castings & A.E.G.S. ${ }^{*}$ & A.G.B.L** \\
\hline Aural-5 & $10.3 \mu \mathrm{m}$ & $6.2 \mu \mathrm{m} / \mu \mathrm{m}^{2}$ \\
\hline Aural-3 [8] & $4.4 \mu \mathrm{m}$ & $11.3 \mu \mathrm{m} / \mu \mathrm{m}^{2}$ \\
\hline
\end{tabular}

*A.E.G.S: Average equivalent grain diameter; ** A.G.B.L: Average grain boundary length

Furthermore, according to the calculated coefficients of TTP curves of the two alloys (see Table 2), AlSi7MnMg exhibits higher values of $k_{2}$ (related to the reciprocal of the number of nucleation sites), $k_{3}$ (corresponding to the nucleus energy), and $k_{5}$ (related to the activation energy for diffusion), than AlSi10MnMg. It implies that the potential nucleation sites in AlSi7MnMg are less than that in AlSi10MnMg, and the nucleation and solute diffusion in the latter are easier and faster than that in the former. This further demonstrates 
that the nucleation and phase growth in AlSi7MnMg are more difficult and slower than that in AlSi10MnMg. Therefore, compared with AlSi10MnMg, the lower concentration of $\mathrm{Mg}$ and $\mathrm{Si}$ in $\mathrm{AlSi} 7 \mathrm{MnMg}$ results in a lower nucleation driving force and larger grain size, consequently the quench sensitivity and phase transformation rate of $\mathrm{AlSi} \mathrm{MnMg}$ are lower than that of AlSi10MnMg.

\section{Conclusions}

1. The TTT and TTP diagrams of AlSi7MnMg (Aural ${ }^{\mathrm{TM}}$ 5) HPVD castings were constructed. The nose temperature is $350{ }^{\circ} \mathrm{C}$ and the quench sensitive temperature range is $260-430{ }^{\circ} \mathrm{C}$. Moreover, the coefficients, $k_{2}-k_{5}$, related to the nucleation and precipitation kinetics of TTP curves, were determined.

2. The cooling rates versus hardness of AlSi7MnMg HPVD castings were predicted and verified by the experimental results. The critical cooling rate of the HPVD castings is $6{ }^{\circ} \mathrm{C} / \mathrm{s}$. When the cooling rate is higher than $6{ }^{\circ} \mathrm{C} / \mathrm{s}$ during quenching, more than $95 \%$ of the maximal mechanical strength can be obtained.

3. The phase transformation diagrams of AlSi7MnMg and AlSi10MnMg (Aural ${ }^{\mathrm{TM}}-3$ ) alloys were determined, and the Avrami constant $k$, and exponent $n$, of the two alloys were determined. The $k$ values of AlSi7MnMg are much lower than that of AlSi10MnMg. The average phase transformation rate of the former is $1 \times 10^{-3} \mathrm{~s}^{-1}$, while the rate of the latter is $3.8 \times 10^{-3} \mathrm{~s}^{-1}$ in the range from 0.2 to 0.8 phase volume fraction at the nose temperatures.

4. AlSi7MnMg exhibits lower quench sensitivity and slower phase transformation rate than AlSi10MnMg. It is mainly due to lower $\mathrm{Mg}$ and $\mathrm{Si}$ concentration in AlSi7MnMg.

\section{Acknowledgments}

The authors would like to acknowledge the financial support of the Natural Sciences and Engineering Research Council of Canada (NSERC) and Rio Tinto Aluminum through the Research Chair in the Metallurgy of Aluminum Transformation at University of Quebec at Chicoutimi.

\section{References}

1. Rio Tinto. Aluminium - Your Guide to Automotive Innovation. Available online: https://www.riotinto.com/documents/Aluminium_Autom otive_innovation_brochure.pdf

2. M. Hartlieb, Die Cast. Eng., 57, 40-43, (2013)

3. X.P. Niu, B.H. Hu, I. Pinwill, H. Li, (2000). J. Mater. Process. Technol. 105, 119-127, (2000).

4. H. Wang, Y. Yi, S. Huang, J. Alloy Compd. 690, 446-452, (2017).
5. J.T. Staley, Mater. Sci. Technol. 3, 923-935, (1987).

6. D.L. Zhang, L. Zheng, (1996). Metall. Mater. Trans. A, 27, 3983-3991, (1996).

7. S. Ma, M. Maniruzzaman, D. MacKenzie, R. Sisson, Metall. Mater. Trans. B, 38, 583-589, (2007).

8. M.Y. Liu, Z. Zhang, F. Breton, X.G. Chen, Materials, 12, 1-13, (2019).

9. J.W. Evancho, J.T. Staley, Metall. Trans. 5(1), 43, (1974).

10. S. Liu, Q. Zhong, Y. Zhang, W. Liu, X. Zhang, Y. Deng, Mater. Des. 31, 3116-3120, (2010).

11. G.E. Totten, G.M. Webster, E.C. Bates, In: Bains T, MacKenzie DS, editors. Proceedings of the first international non-ferrous processing and technology conference, 305-313, (1997).

12. S.D. Liu, X.M. Zhang, J.H. You, Z.B. Huang, C. Zhang, X.Y. Zhang, J. Nonferrous Met., 16, 2034, (2006).

13. M. Avrami, J. Chem. Phys, 7, 1103-1112, (1939).

14. D.A. Porter, K.E. Easterling, M.Y. Sherif, Phase transformations in metals and alloys (CRC Press, Boca Raton, FL, USA, 2009). 